Gender in Management: An International Journal

(C) Emerald Publishing Limited

$1754-2413$

DOI 10.1108/GM-09-2020-0274

\title{
Gendered Experiences of Leading and Managing through COVID-19: Patriarchy and Precarity
}

\author{
Sharon Mavin and Marina Yusupova \\ Newcastle University Business School, Newcastle University, UK
}

\begin{abstract}
Purpose - The purpose of this paper is to highlight key issues for women managers, leaders and precarious academic women during COVID-19 in organisations and in academy.

Design/methodology/approach - This paper shares the authors' personal experiences during COVID19 in the UK as a woman Professor and Director of a Business School and a woman Research Associate and link these with existing scholarship to reflect on areas for continued research and action.
\end{abstract}

Findings - This paper underlines how COVID-19 destabilises the progress made towards gender equality.

Practical implications - This paper outlines future avenues for research and practice as a result of experiences of COVID-19.

Originality/value - This paper looks at the gendered implications of COVID-19 for women across organisational hierarchies and highlights commonalities in their experiences and devastating effects of the pandemic.

Keywords: Gender, Neoliberalism, Patriarchy, Women academics, COVID-19, Women leaders and managers

\section{Introduction}

In what follows we share our personal reflections [1] during COVID-19 in the UK and draw upon existing scholarship with the aim to highlight key issues for women managers, leaders and precarious academic women in organisations and in the academy.

It is the 2nd of July 2020 and we have entered the 5th month of lockdown in the UK. Reflecting on 107 days in COVID-19 lockdown, in what follows we tell some of our stories as a woman Professor and Director of a Business School (a woman leader, researching women leaders) and a woman Research Associate (sociologist, researching women leaders). As white academics working in UK Business Schools, we are privileged in many ways, however, as our reflections show, as women our privilege is precarious, unstable and complex (Mavin and Grandy, 2016). Following our personal reflections, we draw upon previous research in the journal and recent studies of the impact on women of COVID-19 to help us make sense of our experiences. We conclude by providing direct lines of enquiry for future research. 


\section{Personal experiences of a business school director}

Having just completed AACSB reaccreditation (which followed AMBA and EQUIS reaccreditation and Athena SWAN) and led through the second academic national strike in a year, on Wednesday 18th March 2020 we held the first remote School emergency team meeting. By the end of the week, the buildings were closed. This was week one of COVID-19 and I was immediately struck by the fact that the School's catering and reception staff, who are women and those on the lowest salary scales in the hierarchy, were the last people to leave the building and therefore the most at risk.

March-April 2020, universities centralised and academic colleagues were directed to move everything on-line. We had a month, longer than other universities but for a Business School, which does not do any on-line/blended, this was a shock and anxieties increased along with the numbers of people dying in the UK. Significantly, all academic appointments were stopped and I worked overnight to prepare outstanding academic vacancies as a priority for approval. Universities in the UK continued to centralise all decision making with Deans, Directors and Heads of School as communicators of difficult news.

Leading through COVID-19 has involved three and a half months of working 60-70 hours a week and days filled with $9 \mathrm{am}-6 \mathrm{pm}$ in Zoom or Teams meetings before the family ones started. We were sharing with colleagues our children, partners, living areas, dogs, cats, door bells, rows with older children and shopping deliveries, including sofas and furniture. I worked with an incredible and supportive core senior team which was the main positive. However, the overwhelming feelings were around inadequacy in ambiguity; not having the answers at work or at home. I was involving as many people as possible in decisions, then struggling with whether to share the ambiguity with colleagues who were becoming increasingly anxious. I was struck by the inequities in the UK of those who have and those who have not, and how privileged academics are, even when they feel they are not. People responded in different ways; most were brilliant and others became quite seriously horrible. There were no boundaries at all between work-and-life; they permeated each other in ways never experienced before.

At the same time, I felt such grief watching my then 17-year old daughter go through the painful stages for all that she lost: end of School, Prom, A-levels, first holiday abroad with girlfriends, not seeing friends or partner, not doing driving lessons or passing her test, losing all the rites of passage to adulthood, impacting on her emotional, mental and physical health. It was so hard trying to support her when work was so needy and stressful and being at the end of her frustrations when I was not available - yet physically present. Regressing to when were both "little girls" when neither of us were allowed in the kitchen - we baked lemon cake, muffins and learned to make curry. My parents were 40min away shielding; the guilt of not being able to do their direct caring. Feeling envious of those who were doing Joe Wicks workouts, yoga, clearing out houses, gardening, sunbathing and feeling guilty for having a garden. Feeling guilty for having a family and not being alone. Feeling guilty for having a job. Just feeling guilty. It was completely exhausting with little or no sleep and I felt a relentless responsibility for work while feeling terrorised by some, which never went away.

Personally, this has been a different level of extreme in so many ways. COVID-19 has paradoxically been the best and the worst time. After a continual five and a half years as Director in two different Schools and $15 \mathrm{fl}$ years of academic management and leadership before this, I made the decision to stand down from the Director role from31st August 2020.

\section{Personal experiences of a research associate to a business school director}

On the 19th of March 2020, my partner and I had dinner at home. Panic buying of cupboard food and toilet paper has been in full force in the UK, and I suggested that we might consider hording food supplies too, when I got a text message from a Professor and Business School Director, to whom I work as a Research Associate. "See email about equipment" - the text said. The email was there. It explained that tomorrow Friday, 20 March, Business School employees can collect peripherals including screens, keyboards, webcams and office chairs for working from home. As two precariously employed earlycareer academics, working in different parts of the country, commuting by trains and renting flats with weird, never matching and often uncomfortable furniture, we knew immediately - office chairs were a game changer, an opportunity too good to miss. In the next four months, I exclaimed on several occasions - "That chair saved my life! I'm so happy we got it in time". Yet I could not stop wondering how little I needed to get content and why on earth have not I had a comfortable working chair at home 
at the age of 35? Years of precarity have taught me to work from all kinds of ill-fitted places, survive and enjoy life with no stable income, tolerate uncertainty and despair and live in isolation, far away from family and friends. I was well prepared for a social disaster of the COVID-19 epidemic.

At the same time, COVID-19 has intensified precarity. Teaching and research jobs I had applied for in January and February ceased to exist. This time instead of "We regret to inform you that your application has been unsuccessful on this occasion", I received emails saying - "In this unprecedented time we have taken the decision to pause the recruitment process for this vacancy". This was a much scarier message. Still, the remaining 12 months of my contract as a Research Associate overnight turned into a rare luxury and stability as half my office colleagues had less than this. My academic circle of friends - doctoral students with side jobs as language tutors and library assistants, hourly paid "guest" lecturers, unemployed academics with stellar CVs - started howling at the moon. Other friends with permanent jobs or prestigious postdocs who have kids howled twice as much. Three precarious academic mothers with young kids at home reported to me that they could

not focus on work for more than a couple of hours a day. This time was eaten up by emails, recording lectures, marking and paperwork. Reading and writing up for publications were off the list. Considering the centrality of research productivity in recruitment and promotion, COVID-19 has become yet another motherhood penalty.

Compulsory mobility in search of the next academic appointment means that many precarious academics are migrants. My own international career and an opportunity to compete for jobs in the global academic markets came at a price of becoming a transnational mother and living away from my teenage daughter for nine months of a year. Before COVID-19 I was involved in transnational care chains, doing school-related admin via WhatsApp, occasionally helping out with homework, organising groceries and medication for my elderly grandfather. These tasks became my everyday chores during the lockdown taking up 4-5 h a day. Exhaustion from emotional labour, computer screens and information overload accumulated quickly - following countless updates on COVID-19 developments and lockdown measures, entertaining my bored and frightened kid, writing letters to her school administration, coordinating with other parents, guilt and anxiety of not being with family, of being a "bad" mother took a powerful toll on me. It paralysed my normal working routine. Some days were better than others, but I will always remember those three weeks in April when I was barely functioning - frustration, anger, sadness, fatigue and despair took all my mental space.

At the same time, the COVID-19 crisis has had some unexpected positive side effects. Like many other women, I fostered a closer relationship with my child and family despite the physical separation. Spending less money on my social life in addition to the refunds I received from three selffunded academic conferences meant I am in a better financial position to renew my UK visa - a heavy financial and emotional burden for many immigrants.

\section{Gendered realities of COVID-19: glass ceiling, glass cliffs and back to the 1950s}

Sharon's reflections

We thought we had left the glass ceiling behind as a central force in women's careers. In Gender in Management: An International Journal, we have researched the barriers to women's career progression in organisations over so many years, yet this "unprecedented time" has revealed that these were only hovering under the surface, ready to strike back and strike they have!

In 2001, I wrote a paper in this journal about women's careers in theory and practice, identifying how the successful manager remains masculine and while traditional career patterns for modern women continue, women are those who step off to meet family responsibilities and are therefore disadvantaged in their careers. Over the past 20 years, research has shown that women have made significant progress in management and leadership careers. However, COVID-19 has been a driver to place the majority of diverse caring and home responsibilities back into women's hands.

In a 2016 Special Issue, again in this journal, Adelina Broadbridge and I revisited the Glass Ceiling and the "seen" and "unseen" barriers at societal, organisational and individual level (Powell and Butterfield, 2015), which constrain women. These barriers have re-emerged with more power than ever before during COVID-19 and have tremendous impact on women.

Before COVID-19 women's employment was at a record high. However, there is evidence in the UK that women are 7\% more likely than men to have been furloughed or lost their jobs (Sevilla and Smith, 2020); the majority are structurally located in service and retail sectors. Mothers are $47 \%$ more 
likely than fathers to have permanently lost their jobs or quit already and 14\% more likely to have been furloughed (Andrew et al., 2020). As researchers at the University of Bristol and UCL write:

[. . .] women have to put up with over 30 hours of additional childcare a week as children are at home. It is not surprising that some women are giving up working altogether (Sevilla and Smith, 2020).

The burden of additional childcare and unpaid work in the home has fallen far more on mothers particularly among working parents. Mothers are more likely to have had their careers disrupted which risks work and career progression in a context where progress in closing the gender wage gap had already stalled (Blundell et al., 2020). At the University of Sussex, Lester and Lacey (2020) quizzed more than 2,000 parents about the effects of COVID-19 and state that society has regressed to a 1950s way of living, where women are still overwhelmingly taking on role of primary carer and primary educator. Their key findings are shown in Table 1.

Table 1. Women parenting, caring, teaching and work during COVID-19

Findings from Lester and Lacey (2020)

- $72 \%$ of mothers have been the 'default' parent during lockdown prioritising childcare over other things.

- $67 \%$ of mothers who work also said they have been the default parent - despite having a job.

- Pre-COVID-19, 27\% of female respondents reported being responsible for ' $90-100 \%$ of childcare';

- After lockdown started, $45 \%$ of women reported being responsible for ' $90-100 \%$ of childcare'.

- $70 \%$ reported being completely or mostly responsible for supporting children with home-learning, a task associated with considerable time cost.

\section{Gendered realities of COVID-19 in neoliberal universities \\ Marina's reflections}

COVID-19 has intensified precarity in academia and exposed the damage done by years of casualisation. Available evidence demonstrates that despite the neoliberal rhetoric of meritocracy and equal opportunities for success through hard work and commitment (Blackmore, 2006), women in academia experience precarity more acutely than men and for longer. According to O'Keefe and Courtois's (2019) study of casual academic labour in Irish higher education, women on average stay on casual contracts for 7.1 years compared to 5.7 years for men. In 2018/2019 in the UK, women held 42\% of full-time academic positions but $67 \%$ of part-time jobs in universities (HESA, 2020). This trend, beyond doubt, feeds into another pattern of gender inequality in higher education - underrepresentation of women in senior academic ranks. Women constitute a minority among senior academics in many European countries (UK $-26.4 \%$ The Netherlands $-18.7 \%$, France $-21.9 \%$, Germany $-19.4 \%$, Sweden - 25.4\%) (European Commission, 2019, p. 118) and North American countries (USA - 34.4\%, Canada-28\%) (NCES, 2018; Statistics Canada, 2019).

A recent study revealed that women in the USA, the UK and Germany spend more time on childcare and home schooling during the pandemic than men do (Adams-Prassl et al., 2020). This amplifies existing gender inequalities in academia well-documented before the pandemic - lack of mentoring and support for women, lower salaries, men-dominated institutional cultures, student evaluations, which consistently rate men-educators higher that women, subconscious bias in recruitment, teaching allocation, promotion, number of citations and, of course, a maternal wall - "the patterns of bias and stereotyping that affect mothers in particular as opposed to women in general" (Williams, 2005, p. 97). 
In the last academic year there have been two national academic strikes in the UK over the USS pension scheme, the casualisation of work, declining staff pay, the gender pay gap and precarious contracts. The UCU report published in January 2020 noted that:

Nearly 33,000 researchers (67\%) in the sector remain on fixed-term contracts. $49 \%$, nearly 30,000 , teaching "only" staff are employed on fixed-term contracts, many of those hourly paid ( $42 \%$ of all teaching only staff). Add to this over 6500 academic staff employed on zero-hours contracts and an army of nearly 70,000 "atypical" staff (Megoran and Mason, 2020, p. 6).

And yet during COVID-19, all academic appointments were stopped. Being overrepresented in the category of precarious workers on short-term teaching contracts, women, BAME staff, PhD students working as GTAs and international Early Career academics have been heavily impacted by either losing their employment or taking on additional and often unpaid work of switching to online teaching and pastoral care of "distressed students anxious about the completion of coursework in the middle of a pandemic" (O'Keefe and Courtois, 2020). COVID-19 thus exposed the true extent to which British universities are understaffed and inequitable and brought into sharp focus fragility of gender equality gains.

\section{Gendered research production during COVID-19}

Bringing together our reflections, regardless of hierarchy, there are major challenges ahead for women managers, leaders and academics. For women academics, while it may be too early to provide evidence, the Times Higher Education Supplement (2020) has called for the disproportionate effect of COVID19 on women to be addressed and reported on Digital Science's data of women's submission of research outputs. Over the past five years, the proportion of submissions from women had been creeping up, from just below one-third of total submissions, to just over. In May of this year, not only has the total number of submissions plummeted but so has the proportion from women: it's now down to little over one-quarter. Apart from damaging academic women's career prospects, this trend leads to loss of women's expertise from the public domains. We can expect this submission gap to be sustained, if not get worse, as the consequences of global lockdown persist in the months, possibly the years ahead (THES, 2020).

\section{Battling COVID-19 and the patriarchy}

Women are battling COVID-19 and the patriarchy in organisations. A paper in the aforementioned 2017 Glass Ceiling Special Issue, by Simpson and Kumra (2016) has, and continues to have, a profound impact on making sense of experiences as a leader and manager in Higher Education and particularly through this COVID-19 experience. Ruth and Savita introduced a new metaphor, "the Teflon Effect", which highlights the significance of the recognition, performance and embodiment of merit. They outline how merit may fail to "stick" to the bodies of women in management and leadership roles due to a misalignment between social identity (woman) and the nature of the job (leader/manager). This may lead to persistent disadvantage; the glass slipper effect (Ashcraft, 2013), where the occupational identities of manager and leader do not fit women. COVID-19 may personify the misfit of woman and leader. The resilience required to lead as a woman in extreme contexts can be debilitating and sometimes fatal; you may be erased and abjected. COVID-19 has been a period of intense personal reflection by those carrying organisational responsibility. For women, COVID-19 may be interpreted as a gendered example of a "societal" Glass Cliff (Ryan and Haslam, 2007), where women find themselves in precarious leadership positions in ambiguity and high risk, at a distance, "set-up to fail", and men (mostly but not exclusively) question women's suitability to lead change, to make strategic decisions and take on difficult leadership tasks.

In higher education here is a further important battle during COVID-19. As universities tighten budgets, the most vulnerable workers risk reductions or loss of teaching hours while permanent staff face unexpectedly higher workloads. Ensuring a balance between Health and Safety and an Equality Impact assessment without jeopardising teaching quality becomes the main challenge (UCU, 2020).

\section{Provocations for future research}


Our personal reflections of our gendered experiences during COVID-19 have surfaced responsibility, ambiguity, resilience, emotion work, vulnerability, abjection, anxiety, guilt, precarity and have provoked reflexivity. In some ways it does feel like our societal clock just sped backwards. Reflecting on the research and practice in "Gender in Management", our thought piece highlights how COVID-19 destabilises the progress made. Here, we summarise our key points and identify direct lines of enquiry, which are timely, controversial and can be grounded and contextualised within the interdisciplinary fields of gender and management.

It appears that the labour market for academic positions will be intensely competitive and for women this may strengthen the well-documented patriarchal tendencies in UK higher education. Our current research project on women and competition (Mavin and Yusupova, 2020) shows that for women, competition at work is highly problematic and therefore warrants future research which impacts directly on our own practice. In "the new normal" we must step up our battle with patriarchy and investigate the intensification of neoliberalism and its impact on women. There are women step off management and leadership in organisations during the COVID-19 glass cliff. The pandemic is adding numerous "Teflon" coats for women, ensuring merit sticks elsewhere (Simpson and Kumra, 2016) and the glass slipper (Ashcraft, 2013) for managers and leaders is a very difficult fit. A future research avenue is not only to track the number of women in leader positions in various organisational sectors, before and after COVID-19 but also to look throughout the hierarchy at the ranks of precarious women to investigate how the current crisis is providing an environment where patriarchy is re-embedding. This will undoubtedly help to challenge the increasingly hierarchical and inequitable structures of organisations and academia.

\section{Note}

1. Our reflections are personal and not reflective or representative of any university, business school or organisation.

\section{References}

Adams-Prassl, A., Boneva, T., Golin, M. and Rauh, C. (2020), "Inequality in the impact of the coronavirus shock: evidence from real time surveys", IZA Institute of Labor Economics discussion paper series, available at: www.iza.org/publications/dp/13183/inequality-in-theimpact-of-thecoronavirus-shock-evidence-from-real-time-surveys (accessed 4 September 2020).

Ashcraft, K.L. (2013), “The glass slipper: 'incorporating' occupational identity in management studies", Academy of Management Review, Vol. 38 No. 1, pp. 6-31.

Andrew, A., Catton, S., Costa Dias, M., Farquharson, C., Lucy Kraftman, L., Krutikova, S., Phimister, A. and Sevillah, S. (2020), "How are mothers and fathers balancing work and family under lockdown?", Institute of Fiscal Studies, available at: www.ifs.org.uk/publications/14860 (accessed

1 September 2020).

Blackmore, J. (2006), "Deconstructing diversity discourses in the field of educational management and leadership", Educational Management Administration and Leadership, Vol. 34 No. 2, pp. 181-199.

Blundell, R., Joyce, R., Costa Dias, M. and Xu, X. (2020), "Covid-19: the impacts of the pandemic on inequality", Institute of Fiscal Studies, available at: www.ifs.org.uk/publications/14879 (accessed 1 September 2020).

European Commission (2019), "Table 6.1: proportion (\%) of women among academic staff, by grade and total, 2016", She Figures 2018, available at: https://op.europa.eu/en/publication-detail//publication/9540ffa1-4478-11e9-a8ed-01aa75ed71a1/language-en (accessed 4 September 2020).

HESA (2020), "Higher Education Staff Statistics: UK, 2018/19”, Higher Education Statistics Agency, Cheltenham, available at: www.hesa.ac.uk/news/23-01-2020/sb256-higher-education-staff-statistics (accessed 4 September 2020). 
Lester, K. and Lacey, A. (2020), "Coronavirus is sending British society back to the 1950s for many women", available at: www.soundhealthandlastingwealth.com/health-news/coronavirusis-sendingbritish-society-back-to-the-1950s-for-many-women/ (accessed 7 September 2020).

Mavin, S. and Grandy, G. (2016), "Women elite leaders doing respectable business femininity: how privilege is conferred, contested and defended through the body", Gender, Work and Organization, Vol. 23 No. 4, pp. 379-396.

Mavin, S. and Yusupova, M. (2020), “Competition and gender: time's up on essentialist knowledge production", Management Learning, Vol. 1, available at: https://doi.org/10.1177/1350507620950176

Megoran, N. andMason, O. (2020), "Second class academic citizens: the dehumanising effects of casualisation in higher education", University and College Union, available at: www.ucu.org.uk/media/10681/second_class_academic_citizens/pdf/secondclassacademiccitizens (accessed 4 September 2020).

National Center for Education Statistics, IPEDS Data Center (NCES) (2018), "Full-time instructional staff, by faculty and tenure status, academic rank, race/ethnicity, and gender (Degree-Granting institutions): fall 2018”, Fall Staff 2018 Survey, available at: https://nces.ed.gov/ipeds/use-thedata (accessed 4 September 2020).

O'Keefe, T. and Courtois, A. (2019), "Not one of the family': gender and precarious work in the neoliberal university", Gender, Work and Organization, Vol. 26 No. 4, pp. 463-479.

O'Keefe, T. and Courtois, A. (2020), "Who does the 'housework of the university' during a pandemic? The impact of COVID-19 on precarious women working in universities", Gender and Society Blog, available at: https://gendersociety.wordpress.com/2020/06/30/who-does-the-housework-oftheuniversity-during-a-pandemic-the-impact-of-covid-19-on-precarious-women-working-inuniversities/ (accessed 4 September 2020).

Powell, G.N. and Butterfield, D.A. (2015), “The glass ceiling: what have we learned 20 years on?", Journal of Organizational Effectiveness: People and Performance, Vol. 2 No. 4, pp. 306-326.

Ryan, M.K. and Haslam, S.A. (2007), "The glass cliff: exploring the dynamics surrounding the appointment of women to precarious leadership positions", Academy of Management Review, Vol. 32 No. 2, pp. 549-572.

Sevilla, A. and Smith, S. (2020), "Baby steps: the gender division of childcare during the COVID19 pandemic", University of Bristol, available at: www.bristol.ac.uk/news/2020/may/childcare inlockdown.html (accessed 1 September 2020).

Simpson, R. and Kumra, S. (2016), "The Teflon effect: when the glass slipper meets merit", Gender in Management: An International Journal, Vol. 31 No. 8, pp. 562-576.

Statistics Canada (2019), "Number and salaries of full-time teaching staff at Canadian universities (final), 2018/2019", The Daily, available at: www150.statcan.gc.ca/n1/dailyquotidien/191125/dq191125b-eng.htm (accessed 1 September 2020).

Times Higher Education Supplement (2020), "The disproportionate effect of COVID-19 on women must be addressed", available at: www.timeshighereducation.com/opinion/disproportionateeffectcovid-19-women-must-be-addressed (accessed 13th July).

UCU (2020), "Four questions to ask your line manager", available at: https://qmucu.org/fourquestionsto-ask-your-line-manager/ (accessed 1 September). 
Williams, J.C. (2005), "The glass ceiling and the maternal wall in academia", New Directions for Higher Education, Vol. 2005 No. 130, pp. 91-105.

\section{Further reading}

Broadbridge, A. and Mavin, S. (2016), "Editorial: beyond the glass ceiling and metaphors", Gender in Management: An International Journal, Vol. 31 No. 8, pp. 502-513.

Mavin, S. (2001), "Women's career in theory and practice: time for change?", Women in Management Review, Vol. 16 No. 4, pp. 183-192.

The authors received no financial support for the research, authorship, and publication of this article.

\section{Biographical Details:}

Professor Sharon Mavin is Professor of Leadership and Organisation Studies and former Director at Newcastle University Business School. A Fellow of the Royal Society of Arts, Academy of Social Sciences and British Academy of Management, she is Chair of the Chartered Association of Business Schools Diversity and Inclusion Committee and Chair of the University Forum of HRD. Sharon's recent research projects concern women elite leaders, gendered media, vulnerability and dirty work with recent publications in Management Learning, human relations and Gender, Work and Organization.

Marina Yusupova is a sociologist and postdoctoral researcher at Newcastle University, currently working on the project 'Women Leaders: Ambition, Competition and Friendship'. She has a PhD from the University of Manchester (2017) and has previously been a Fulbright Visiting Scholar at Stony Brook University (USA) and Aleksanteri Fellow at the University of Helsinki (Finland). Research interests include gendered leadership, feminist and queer theories in non-Western contexts, race and coloniality, critical men and masculinities studies. 